\title{
UHPFRC tensile creep at early age
}

\author{
A. Kamen · E. Denarié · H. Sadouki $\cdot$ E. Brühwiler
}

Received: 2 August 2007 / Accepted: 3 March 2008/Published online: 11 March 2008

(C) RILEM 2008

\begin{abstract}
Ultra high performance fibre reinforced concrete (UHPFRC) early age viscoelastic behaviour under tension was investigated. The tests results showed a high creep potential due to the high volume paste $(88 \%)$. This result is of major importance because the viscoelastic properties contribute to mitigating the high early age stresses generated under restrained shrinkage. This beneficial effect was reflected by the increased linear-relationship between tensile creep and shrinkage. As expected, UHPFRC tensile creep behaviour was also sensitive to the loading level. Above $35 \%$ of the tensile strength at the loading age, the material exhibited viscoplastic behaviour. A Maxwell chain model was applied to predict the early age UHPFRC tensile creep and confirms the induced non-linear response.
\end{abstract}

Résumé Le comportement viscoelastique en traction au jeune âge du Béton Fibré Ultra Performant (BFUP) a été étudié. Les résultats d'essais ont montré que le matériau est caractérisé par un potentiel élevé de fluage attribué au grand volume de pâte contenu dans le BFUP (88\%). Ces résultats sont d'une importance majeure $d u$ fait que les propriétés viscoélastiques contribuent à atténuer les

A. Kamen $(\varangle) \cdot$ E. Denarié $\cdot$ H. Sadouki · E. Brühwiler Laboratory of Maintenance and Safety of Structures (MCS), Ecole Polytechnique Fédérale de Lausanne (EPFL), Station 18, 1015 Lausanne, Switzerland e-mail: aicha.kamen@epfl.ch autocontraintes susceptibles de se produire au jeune âge sous certaines conditions d'entrave. Cet effet bénéfique est reflété par la relation linéaire croissante entre le fluage en traction et le retrait. Comme attendu, le comportement viscoélastique du BFUP est sensible aux niveaux de sollicitation. Au-delà de $35 \%$ de la résistance à la traction à l'âge de sollicitation, le matériau présente un comportement viscoplastique. Le modèle de Maxwell généralisé a été appliqué pour prédire le fluage en traction au jeune $\hat{a g e}$, son application confirme la réponse non-linéaire observée.

Keywords UHPFRC · Early age · Numerical model $\cdot$ Tensile creep

\section{Introduction}

Structures are subjected during their service life to numerous loads: self-weight, live, wind, earthquake loads and temperature and relative humidity changes. In addition, under certain structural and environmental conditions, structures are subjected to internal stresses generated by early age restrained deformations; potentially compromising the durability of newly constructed or repaired structures due to macrocrack formation. Thus, it is important to characterize the early age behaviour under tensile loading. 
The majority of research related to creep of cementitious materials published in the literature analyses compressive creep because tensile creep tests are much more complicated to perform, especially on young concrete. Thus, such tests are rare [1-5]. According to Altoubat and Lange [6, 7], the scarcity of tensile creep tests is due, to their complexity and to the simultaneous physical and chemical properties variations at early age complicating their interpretations. Moreover, data on nonlinearity in tension are limited. One notes that the investigation of nonlinear tensile creep is relevant because such behaviour can be achieved in specific structures (under particular structural and environmental conditions) due to the high induced tensile stresses.

Temperature Stress Testing Machine (TSTM) was initially used to measure autogenous shrinkage and induced stresses since very early age (few minutes after mixing) [8], and was later employed to study tensile viscoelastic behaviour [9]. The TSTM is an adapted testing system to investigate early age tensile creep behaviour of young cementitious materials.

UHPFRC early age tensile viscoelastic behaviour is still not completely known. According to our knowledge, little attention has been given to UHPFRC early age tensile viscoelastic behaviour $[10,11]$. Besides, it was shown previously that high volume paste cementitious materials have high creep potential under compressive loading [12].

However, in the last decade's substantial attention has been invested to evaluating and modelling tensile creep in other cementitious materials including cement pastes, normal and high performance concretes. Indeed, viscoelastic properties contribute to decrease the early age cracking risk thanks to its beneficial role in mitigating the early age stresses under restrained conditions $[2,4,5,9,13]$. The focus of this research is to investigate UHPFRC early age behaviour particularly: autogenous shrinkage and tensile creep under sealed conditions (no exchange with the environment i.e. humidity and temperature controlled) and various stress/strength levels.

An accurate structural analysis considering stresses and cracking damage can only be achieved by correctly modelling the viscoelastic material behaviour. This paper reports on a series of UHPFRC material investigation to answer the following questions: (1) How does the age of loading influence the
UHPFRC tensile creep behaviour? (2) At what stress/ tensile strength level does the strain-stress proportionality ceases? (3) Can existing models be applied to predict UHPFRC tensile creep?

\section{Material}

UHPFRC of the CEMTEC ${ }_{\text {multiscale family [14] is }}^{\circledR}$ produced by adding to ultra-compact cementitious matrix microfibres (steel wool); they have a semicircular section, with variable dimensions $(2-7 \mathrm{~mm})$ and present an irregular aspect ratio allowing a high adhesion with cementitious matrix. And straight steel fibres (6\%), with $10 \mathrm{~mm}$ length and $0.2 \mathrm{~mm}$ diameter and aspect ratio of 50 . The total percentage of fibres being $9 \%$.

The ultra compact matrix is composed of: (1) cement with low content of $\mathrm{C}_{3} \mathrm{~A}$, thus minimizing its water demand, (2) silica fume (by product of zirconium production) in high amount (26\% by weight of cement), (3) fine quartz sand $(0.5 \mathrm{~mm}$ maximum grain size), (4) water and (5) superplasticizer in liquid form (solid content of approx. 30\%), in high percentage ( $3.3 \%$ by weight of cement). The water content in the percentage is included in the water to cement ratio (W/C). The Chemical compositions of the cement and the silica fume are given in Table 1 and the mix proportions of the tested UHPFRC are given in Table 2.

Table 1 Chemical compositions of the cement and the silica fume

\begin{tabular}{lcl}
\hline Component & Cement $(\%)$ & Silica fume $(\%)$ \\
\hline $\mathrm{SiO}_{2}$ & 22.75 & 93.5 \\
$\mathrm{Al}_{2} \mathrm{O}_{3}$ & 2.70 & 3.5 \\
$\mathrm{Fe}_{2} \mathrm{O}_{3}$ & 1.90 & 0.15 \\
$\mathrm{CaO}$ & 67.10 & 0.02 \\
$\mathrm{MgO}$ & 0.75 & - \\
$\mathrm{K}_{2} \mathrm{O}$ & 0.20 & 0.06 \\
$\mathrm{Na}_{2} \mathrm{O}$ & 0.15 & 0.10 \\
$\mathrm{SO}_{3}$ & 2.10 & $60 \mathrm{ppm}$ \\
$\mathrm{Insolubles}$ & 0.30 & - \\
$\mathrm{ZrO}_{2}$ & - & 2.4 \\
$\mathrm{CO}_{2}$ & 1.30 & - \\
$\mathrm{CaO}$ free & 0.55 & - \\
$\mathrm{PF}$ & 1.90 & 0.5 \\
\hline
\end{tabular}


Table 2 UHPFRC recipe

\begin{tabular}{llr}
\hline Material & Type & Weight $\left(\mathrm{kg} / \mathrm{m}^{3}\right)$ \\
\hline Cement & CEM I 52.5 N CE PM-ES-CP2 NF, Lafarge, & 1410.2 \\
le Teil, specific surface 3,400 $\mathrm{cm}^{2} / \mathrm{g}$ & 367 \\
Silica fume & SEPR (median diameter $=0.5 \mu \mathrm{m}$, specific surface $\left.12 \mathrm{~m}^{2} / \mathrm{g}\right)$ & 80.4 \\
Fine sand & Sand of Fontainebleau, MN $30(<0.5 \mathrm{~mm})$ & 200.1 \\
Water & 200.1 & 46.5 \\
Superplasticizer & Chryso-Fluid-OPTIMA 175 & 706.5 \\
Steel fibres (macro and micro) & Macro: straight and micro: wool & \\
\hline
\end{tabular}

The specific UHPFRC used in this study exhibits an extremely low permeability, a high strength and a pronounced tensile strain hardening behaviour [10, 15]. Despite its very low water/binder ratio (0.130), it exhibits excellent rheological properties in the fresh state due to its high binder content.

The mean UHPFRC properties in fresh and harden sates are presented in Table 3, the compressive strengths and modulus of elasticity were determined on 11/22 cm cylinders. And uniaxial tensile strength and magnitude of tensile hardening were determined on unnotched dogbone specimens of $70 \mathrm{~cm}$ length and $10 \times 5 \mathrm{~cm}^{2}$ cross section.

Table 3 UHPFRC properties

\begin{tabular}{lllr}
\hline Property & Units & Mean value & Age \\
\hline Slump flow & $(\mathrm{cm})$ & 65 & - \\
Air content & $(\%)$ & 1.8 & - \\
First crack strength of UHP matrix & $(\mathrm{MPa})$ & 12 & 90 \\
Uniaxial tensile strength & $(\mathrm{MPa})$ & 14 & 90 \\
Modulus of elasticity & $(\mathrm{MPa})$ & 47,200 & 28 \\
Compressive strength & $(\mathrm{MPa})$ & 192.4 & 28 \\
Magnitude of tensile hardening & $(\%)$ & 0.15 & 90 \\
\hline
\end{tabular}

This UHPFRC's outstanding properties make it an ideal material for hardening composite reinforced concrete structural members. This UHPFRC has been employed since 2004, under the direction of maintenance and safety of structures laboratory (MCS), to rehabilitate a 50-year old road bridge, a crash barrier and a bridge pies in Switzerland that have been significantly damaged by corrosion $[16,17]$.

\section{Experiments}

\subsection{Testing procedure}

The early age tensile creep tests were conducted for 1 week on temperature controlled dog-bone shaped specimens with $50 \times 100 \mathrm{~mm}^{2}$ linear cross section and 1,000 mm length, using a TSTM machine placed in a climatically controlled room at $20^{\circ} \mathrm{C}$ and $65 \%$ $\mathrm{RH}$. In each specimen the distance between the set of LVDT is $750 \mathrm{~mm}$. The TSTM was developed during the first authors' doctoral thesis [18] based on previous research $[4,19,20]$. The first device of the TSTM helps to determine the free shrinkage (FS) (Fig. 1a). And the second one gives the total deformation under restrained deformation (RS) (Fig. 1b).
Fig. 1 TSTM set up: (a) free shrinkage (FS) and (b) restrained shrinkage (RS)
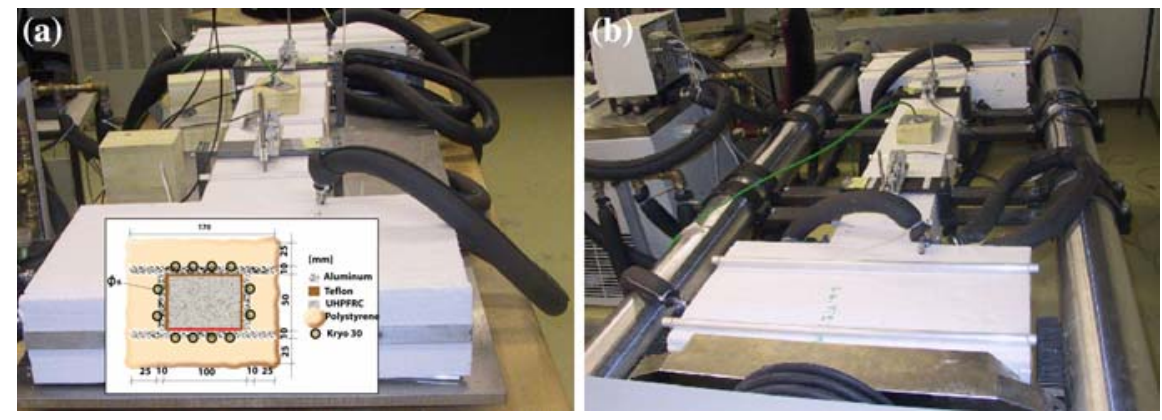


\section{$\varepsilon[\mu \mathrm{m} / \mathrm{m}]$}

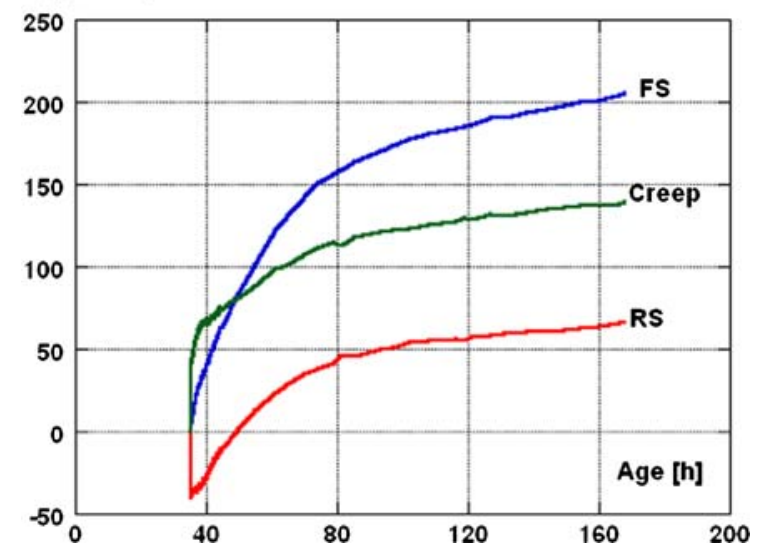

Fig. 2 Experimental results in FS and RS devices during creep test under loading stress at $35 \mathrm{~h}$ and the resulting tensile creep including elastic deformation

The tests results issues from the two devices allow the calculation of the basic creep including elastic deformation by subtraction of the response measured in the RS device from the autogenous shrinkage at the age of loading (see example showed in Fig. 2). In this investigation, different loading ages (35, 46 and $72 \mathrm{~h}$ ) and stress/strength levels (between $30 \%$ and 63\%) were considered.

The experimental data was then used to model the UHPFRC early age time dependent behaviour with rheological models and to determine the level of onset of non linearity in the viscous response.

\subsection{Tests results and discussion}

The UHPFRC creep test results performed on specimens loaded at 3 days at two stress/strength levels
$32 \%$ and $63 \%$ (Fig. 3a) are presented in Fig. 3b. Note that in those figures test 1 refers to the test performed under a low stress/strength level $32 \%(\sigma=1.2 \mathrm{MPa})$ and tests 2 and 3 refer to the two tests performed under the higher stress/strength level 63\% $(\sigma=2.4 \mathrm{MPa})$. From Fig. 3b, one can observe that the early age creep rate is significant, because a most part of the creep deformation occurs in the first hours after loading.

For the low stress/strength level 32\% $(\sigma=1.2 \mathrm{MPa})$, the creep evolution stabilizes within the $80 \mathrm{~h}$ following loading. This means that the major part of the tensile creep occurs at early age and thus allows mitigation of induced stress under restrained conditions, which can appear during this period. This early age creep under the low stress/strength level corresponds to $40 \%$ of the autogenous shrinkage. This finding is in agreement with results obtained by Altoubat and Lange [6]. The authors also observed that the tensile creep rate is higher at early age for concrete and fibre reinforced concrete, during the first 10-20 $\mathrm{h}$ after loading, then reaches a stable value.

At the end of the test (1) under the low stress/ strength level $(32 \%)$, the measured creep slightly decreased. In the current state, our analysis does not point at a specific explanation for this phenomenon, but it may be caused by the strong concentration in fibres in the current specimen that can be at the origin of this creep reduction. Indeed, initially the matrix flows then due to the internal stress redistribution, fibres can contribute in stress bearing. Besides, the on-going hydration process can also contribute to the phenomenon. In fact, the mechanical strengths and stiffness increase and induced a gradual reduction of creep capability over time.
Fig. 3 (a) Loading stress at $72 \mathrm{~h}$ and (b) tensile creep including elastic deformation after $72 \mathrm{~h}$

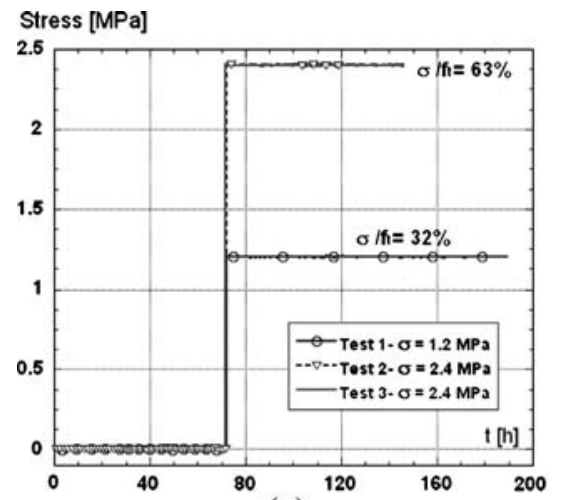

(a)

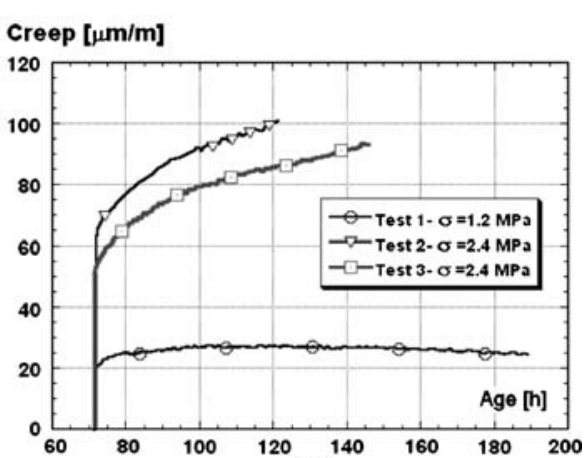

(b) 
Under high stress/strength level 63\% (2.4 MPa) corresponding to tests (2) and (3), in Fig. 3a, high deformations were observed indicating a viscoplastic response primarily induced by micro-cracking. This stress/strength level is beyond the linear domain with continuously increasing deformation within the time. Indeed, previous research has found that an early age compressive creep test under stress/strength level higher than $40 \%$ can induce a non-linear behaviour [21]. Likewise, the tests performed by Atrushi [22] on HPC (high performance concrete) with a w/b $=0.40$ showed that the proportionality limit occurred at $60 \%$ of the tensile strength.

The reproducibility of the test results shown in Fig. 3b (referred by test (2) and (3)), confirmed the efficiency of the experimental setup to characterize the tensile creep at early age.

The creep tests performed at 35 and $46 \mathrm{~h}$ loading ages (Fig. 4a) are presented in Fig. 4b. The results showed as expected, that tensile creep response is sensitive to the loading age. The creep amplitude increased when the specimens are loaded at early age i.e. the creep is inversely correlated with loading age, due to the lower material stiffness at early age. These results confirmed again the non-linear behaviour at $50 \%$ (stress/strength).

\subsection{Correlation between autogenous shrinkage and tensile creep}

The relationship between the current UHPFRC autogenous shrinkage and the specific tensile creep is presented in Fig. 5, where the specific tensile creep $\mathrm{J}\left(\mathrm{t}, \mathrm{t}_{0}\right)(\mu \mathrm{m} / \mathrm{m} / \mathrm{MPa})$ represents the strain at age $(\mathrm{t})$ produced by a unit constant stress applied at age $\left(\mathrm{t}_{0}\right)$. Figure 5 shows a linear increasing correlation between the autogenous shrinkage and the specific tensile creep indicating that this UHPFRC has a capacity to shrink without cracking at early age.

Indeed, the stresses generated by the autogenous shrinkage, in the RS set-up were also determined under total restrained conditions (results not included in this paper), see references $[18,23,24]$. The induced stress reached at 7 days, $30-47 \%$ of the rupture strength under tension $(\sigma \mathrm{t})$ obtained at the end of each test. In addition, others specimens were visually
Fig. 4 (a) Loading stress at $35,46 \mathrm{~h}$ and (b) resulting tensile creep including elastic deformation

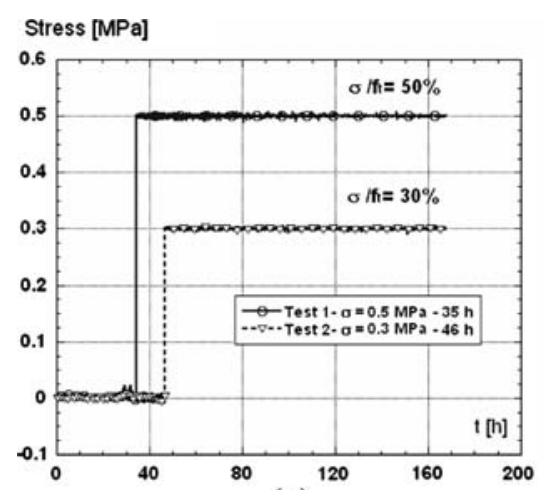

(a)

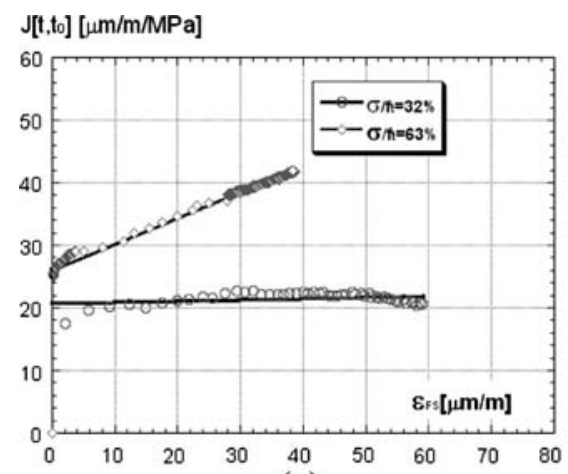

(a)

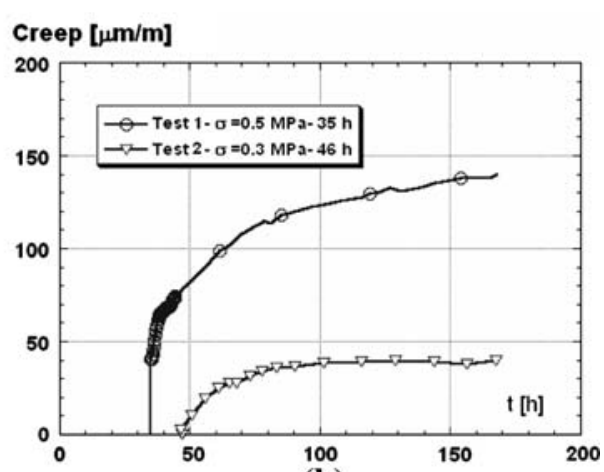

(b)

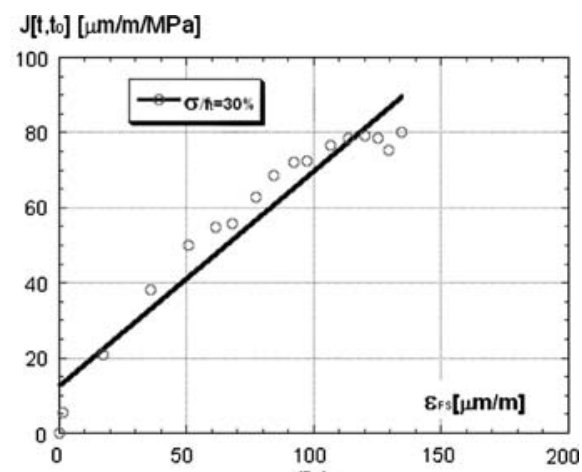

(b)

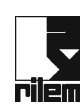

Fig. 5 Correlation between autogenous shrinkage and specific tensile creep after: (a) $72 \mathrm{~h}$ and (b) $46 \mathrm{~h}$ 
analysed at the end of incremental test and no cracks were detected. However, some micro-cracks can exist at this stage but they are not damageable as the specific material has a high ductility and is characterized by a high tensile strength and a high capacity of deformation $(0.2 \%$ in the hardening domain), consequently reducing its early age cracking sensitivity at such stress levels.

Bissonnette et al. [25] found a similar relationship for normal concrete. According to the authors, this linear correlation is an important characteristic that should be used to evaluate materials designed for composite rehabilitation applications from a compatibility point of view, as the creep mitigates a portion of the induced stresses under restrained conditions (relaxation). A similar autogenous shrinkage and the compressive creep relationship was observed for the current UHPFRC [18] and for normal concrete [26].

\subsection{Stress/strength level effect on tensile creep}

The thresholds (35\%, 65\% and 90\%) presented schematically in Fig. 6 are proposed to differentiate the various UHPFRC responses under tensile stress:

- Domain $1\left(\sigma / \mathrm{f}_{\mathrm{t}}<35 \%\right)$ : the UHPFRC presents a viscoelastic behaviour and the deformation-stress proportionality hypothesis is valid within this limit.

- Domain $2\left(35 \%<\sigma / \mathrm{f}_{\mathrm{t}}<65 \%\right)$ : the UHPFRC presents a viscoplastic behaviour and non-linear

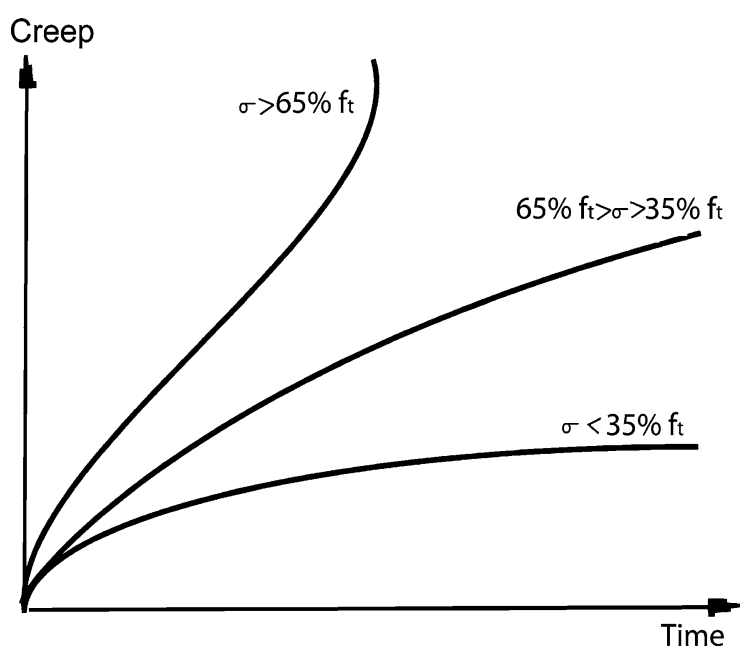

Fig. 6 Tensile creep response under different loading stress level creep due to the simultaneous interaction of microcracking. Above 35\% stress/strength level, the deformation-stress proportionality ceases. Neville and Brooks [27] placed the interaction of micro-crack and nonlinearity transition point at $40-50 \%$ of stress/strength.

- Domain $3\left(\sigma / \mathrm{f}_{\mathrm{t}}>65 \%\right)$ : Stresses are close to the material tensile strength inducing tertiary creep and local instability resulting in sudden high deformation and loss of carrying capacity.

Finally, we can conclude that the stress/strength thresholds proposed here are correct at least for this material. These values must be validated by further experiments. There is, therefore, more work to be made in this field, because it is necessary to characterize and predict correctly the early age viscoelastic behaviour of this specific cementitious material, which is determining parameter in the structural response under restrained conditions.

\section{Modelling}

\subsection{Aging creep model based on Kelvin chains}

The model proposed by Bazant and Prasannan [28] based on the solidification theory to describe the tensile basic creep under a constant stress was simplified by Altoubat and Lange [6] and expressed as function of two main parameters $\mathrm{v}(\mathrm{t})$ and $\left(1 / \mathrm{E}_{\mathrm{i}}\right)$, Eq. 1.

$$
\begin{aligned}
\varepsilon_{\text {creep }}= & \frac{\sigma}{\mathrm{v}(\mathrm{t})}\left[\mathrm{A}_{1}\left(1-\mathrm{e}^{-\left(\mathrm{t}-\mathrm{t}_{0}\right) / \tau_{1}}\right)+\mathrm{A}_{2}\left(1-\mathrm{e}^{-\left(\mathrm{t}-\mathrm{t}_{0}\right) / \tau_{2}}\right)\right. \\
& \left.+\cdots+\mathrm{A}_{\mathrm{N}}\left(1-\mathrm{e}^{-\left(\mathrm{t}-\mathrm{t}_{0}\right) / \tau_{\mathrm{N}}}\right)\right]
\end{aligned}
$$

where $t(h)$ is the age, $t_{0}(h)$ is the age at loading, $A_{i}=1 / E_{i}(-), \tau_{i}$ are constant for the ith unit of the Kelvin chain and $\mathrm{v}(\mathrm{t})(-)$ is volume fraction growth characterizing the aging, and is expressed by Eq. 2 .

$\frac{1}{\mathrm{v}(\mathrm{t})}=\left(\frac{\lambda_{0}}{\mathrm{t}}\right)^{\mathrm{m}}+\alpha$

where $\lambda_{0}(\mathrm{~h})$ is a constant equal to $24 \mathrm{~h}$ and $\mathrm{m}$ and $\alpha(-)$ are nondimensional empirical constants.

After several calculations, three retardation times ( $\tau=1,10$ and $100 \mathrm{~h}$ ) were selected to account of all 
Table 4 Model parameters

\begin{tabular}{ll}
\hline Age (days) & 3 \\
$\sigma(\mathrm{MPa})$ & 1.2 \\
$\mathrm{~m}(-)$ & 0.399 \\
$\alpha(-)$ & 2.245 \\
E1 (-) & $1.50 \mathrm{E}^{+05}$ \\
E2 (-) & $1.23 \mathrm{E}^{+06}$ \\
E3 (-) & $9.47 \mathrm{E}^{+05}$ \\
\hline
\end{tabular}

the testing period. The model parameters $\mathrm{m}, \alpha$ and $\mathrm{E}_{\mathrm{i}}$ (given in Table 4) were determined by the least square minimization process. The current model parameters are valid only for this age of loading i.e. $72 \mathrm{~h}$ and for stress/strength lower than the threshold limit of linearity of creep.

The obtained results (Fig. 7) confirm that this model describes the UHPFRC early age behaviour

\section{$\mathrm{J}\left(\mathrm{t}, \mathrm{t}_{\mathrm{o}}\right)[\mu \mathrm{m} / \mathrm{m} / \mathrm{MPa}]$}

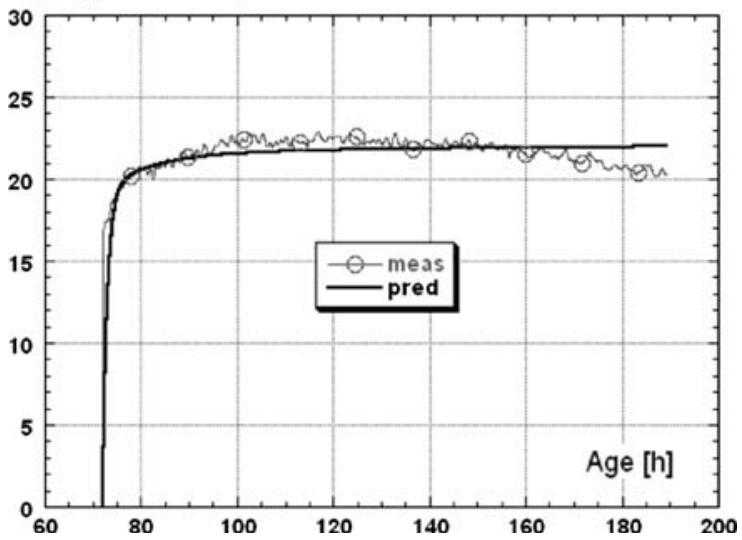

Fig. 7 Aging creep model based on Kelvin chains according to Altoubat and Lange [6]

Fig. 8 Relaxation fit by Prony series at: (a) $46 \mathrm{~h}$ and (b) $72 \mathrm{~h}$

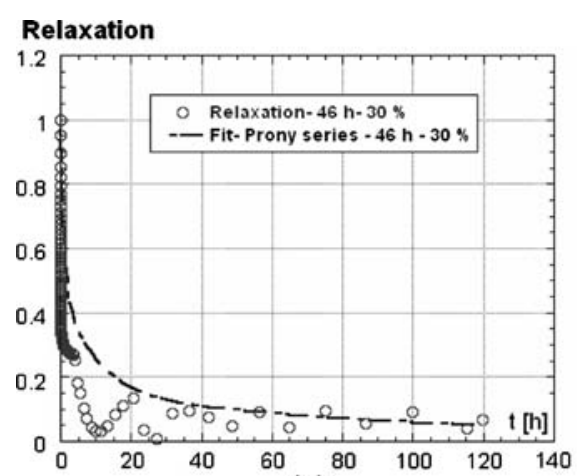

(a) very well and can be implemented in a finite element software.

\subsection{Maxwell chains model}

UHPFRC creep is predicted using Maxwell's chain model, Eq. 3. The model predicts in the linear domain, for any viscoelastic material, the stress history from a given strain history by means of a step by step algorithm that is based on equations presented in detail in references [29-31]. This algorithm converts the experimental results or the creep function into relaxation, which can be then represented by the Maxwell chains model. The Maxwell chains model parameters can then be determined by fitting a function noted Prony series to the relaxation curve.

$\mathrm{E}\left(\mathrm{t}, \mathrm{t}_{0}\right)=\mathrm{E}_{\mathrm{c}} \sum_{\mathrm{i}=1}^{\mathrm{m}} \beta_{\mathrm{i}} \cdot \mathrm{e}^{-\left(\mathrm{t}-\mathrm{t}_{0}\right) / \tau_{\mathrm{i}}}$

where $\mathrm{E}$ is relaxation, $\tau_{\mathrm{i}}(\mathrm{h})$ is retardation time and $\beta_{\mathrm{i}}(-)$ is a factor whose sum is equal to $1, \mathrm{t}(\mathrm{h})$ is the current age and $t_{0}(h)$ is the loading age.

Application of this step-by-step algorithm to our tensile creep experimental results gives the relaxation curves shown in Fig. 8a, b.

The Maxwell chains model parameters (presented in Table 5) were obtained by fitting the transformed relaxation curves.

Table 5 Maxwell's chains model parameters (-)

\begin{tabular}{lllllll}
\hline Age $(h)$ & \multicolumn{6}{l}{ Retardation time $(\mathrm{h})$} \\
\cline { 2 - 7 } & 1 & 10 & 100 & 1,000 & 10,000 & 100,000 \\
\hline 46 & 0.5200 & 0.3300 & 0.1400 & 0.0100 & 0.0000 & 0.0000 \\
72 & 0.0600 & 0.1052 & 0.1591 & 0.0211 & 0.0107 & 0.6439
\end{tabular}




\subsection{Tensile creep test numerical simulations}

The aim of this numerical simulation is to predict the UHPFRC tensile creep using a finite element software MLS (Multi Layer System), which considers several phenomena and their interactions through thermal, hygral, maturity and mechanical models. Further details concerning the models can be found in [32-34]. These numerical simulations aimed to validate the identified Maxwell chains model and to confirm the non-linear response.

The input data for these numerical simulations are obtained from experimental results namely: the thermal properties, the compressive strength, tensile strength, elastic modulus. For this numerical simulations only the linear part of the TSTM specimen is considered, the dimensions and the boundary conditions considered for these simulations are shown in Fig. 9.

These simulations results confirm that the Maxwell model can be applied to predict the UHPFRC tensile creep, as long as the element remains in the linear domain, see Fig. 10a. Once the Maxwell model parameters are obtained for the different loading ages (46 and $72 \mathrm{~h}$ ), the experimental UHPFRC behaviour i.e. the total deformation including the autogenous shrinkage measured with the TSTM is accurately predicted [18].

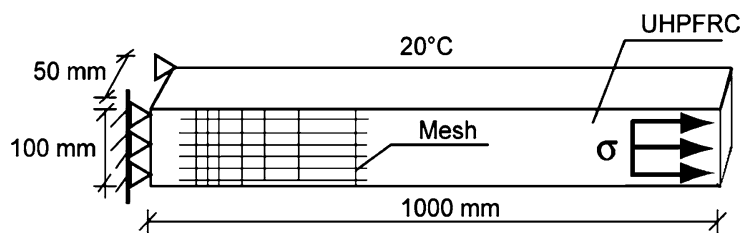

Fig. 9 Dimensions and boundary conditions for tensile creep prediction
Within the non-linear domain, $(\sigma / \mathrm{ft}=50 \%)$ Fig. $9 b$, the experimental creep surpasses the predicted response. Within this non-linear domain, the damage mechanism modifies the material's response. This modification (additional deformation due to micro-cracking) is not considered by the generalized Maxwell model. This limitation is confirmed by the results showed in Fig. 11, which presents both the experimental and the predicted results at $72 \mathrm{~h}$ and under high stress/strength level $(\sigma / \mathrm{ft}=63 \%)$.

\section{Conclusions}

- Experiments performed on UHPFRC confirm that this material has a high early age tensile creep which is attributed to the material mixture specificity i.e. the high amount of silica fume and the high volume of paste $(88 \%)$.

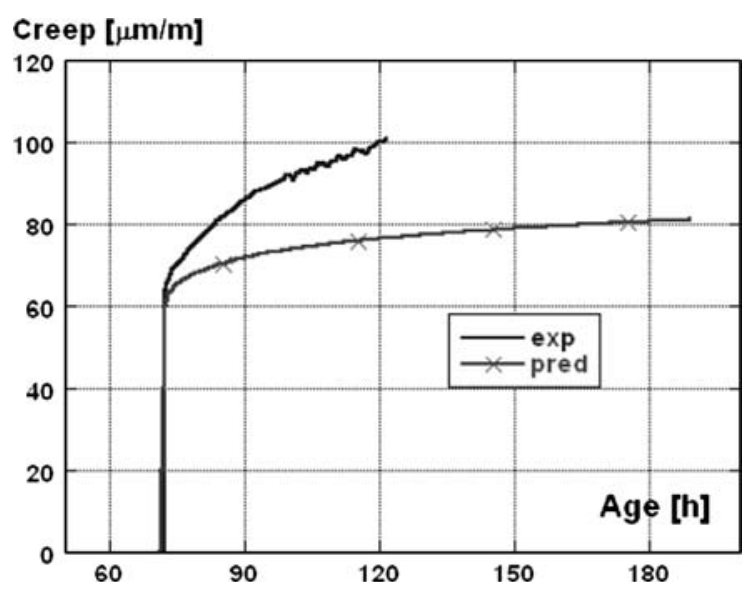

Fig. 11 Experimental and predicted tensile creep results including elastic deformation under $\sigma / \mathrm{ft}=63 \%$ at $72 \mathrm{~h}$
Fig. 10 Experimental and predicted tensile creep results including elastic deformation under (a) $\sigma / \mathrm{ft}=30 \%$ and (b) $\sigma / \mathrm{ft}=50 \%$

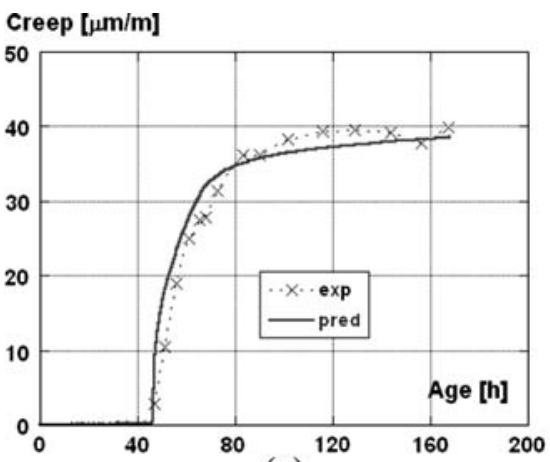

(a)

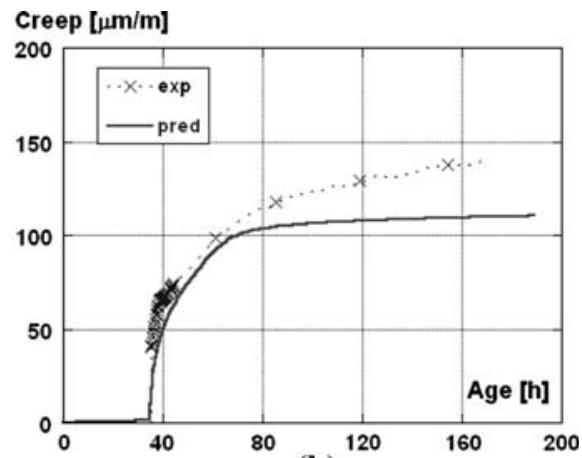

(b) 
- The studied UHPFRC exhibits viscoplastic behaviour when loaded under high stress/strength level $(50 \%$ and $63 \%)$.

- A linear increasing correlation was found between shrinkage and specific tensile creep.

- The Maxwell chains and Kelvin chains models are valid to predict the UHPFRC viscoelstic behaviour as long as the tensile stress remains inferior to creep linearity threshold.

- Under high stress/strength levels, the experimental creep is higher than that predicted by the Maxwell model, which is valid only in the linear domain. Although, there is a large number of creep functions and models, more investigation are needed to adapt the existing models or to develop new one capable to reproduce the effect of the stress/strength level on the cementitious materials creep, that only few existing models allow to describe, for instance Bazant and Prasannan model. Besides, in the composite structures, the non linearity due to the high induced tensile stresses susceptible to develop at the young age under restrained conditions is a relevant problem.

Acknowledgements This project is financially supported by the Swiss National Science Foundation and the Swiss Federal Office for Education and Science within the European project "Sustainable and Advanced Materials for Road Infrastructures" (SAMARIS). The authors want to thank Roland Gysler for his help in performing the tests and Jim birsall for his English corrections.

\section{References}

1. Bissonnette B (1996) Le fluage en traction: un aspect important de la problématique des réparations minces en béton. Ph.D. thesis, The University of Laval, Québec, Canada, 290 pp (in French)

2. Igarashi S, Bentur A, Kovler K (2000) Autogenous shrinkage and induced restraining stresses in high-strength concretes. Cem Concr Res 30:1701-1707

3. Toma G (1999) Comportement des bétons au jeune âge. Ph.D. thesis, The University of Laval, Canada, 262 pp (in French)

4. Charron J-P (2003) Contribution à l'étude du comportement au jeune âge des matériaux cimentaires en conditions des déformations libre et restreinte. Ph.D. thesis, The University of Laval, Québec, Canada, 332 pp (in French)

5. Bosnjak D (2000) Self-induced cracking problems in hardening concrete structures. Doctoral thesis, The University of Trondheim, Norway, $152 \mathrm{pp}$
6. Altoubat SA, Lange DA (2001) Tensile basic creep: measurements and behavior at early age. ACI Mater J 98(5):386-393

7. Altoubat SA, Lange DA (2001) Creep, shrinkage, and cracking of restrained concrete at early age. ACI Mater $\mathbf{J}$ 98(4):323-331

8. Paillère AM, Buil M, Serrano JJ (1989) Effect of fiber addition on the autogenous shrinkage of silica fume concrete. ACI Mater J 86:139-144

9. Kovler K, Igarashi SI, Bentur A (1999) Tensile creep behavior of high strength concretes at early ages. Mater Struct 32(219):383-387

10. Habel K (2004) Structural behaviour of elements combining ultra-high performance fibre-reinforced concretes (UHPFRC) and concrete. Doctoral thesis No. 3036, The Ecole Polytechnique Fédérale de Lausanne, Suisse, $195 \mathrm{pp}$

11. Habel K, Charron J-P, Denarié E, Brühwiler E (2006) Autogenous deformations and viscoelasticity of UHPFRC in structures; Part I: experimental results and Part II: numerical modeling. Mag Concr Res 58(3):135-156

12. Loukili A (1996) Etude du retrait et du fluage de Bétons à Ultra-Hautes Performances. Doctoral thesis, The Ecole Centrale de Nantes, France, 155 pp (in French)

13. Rostasy FS, Gutch A, Laube M (1993) Creep and relaxation of concrete at early ages-experiments and mathematical modelling, in creep and shrinkage of concrete. In: Proceedings of the 5th international RILEM symposium in Barcelona

14. Rossi P, Arca A, Parant E, Fakhri P (2005) Bending and compressive behaviors of new cement composite. Cem Concr Res 33:27-33

15. Charron J-P, Denarié E, Brühwiler E (2004) Permeability of UHPFRC under high stresses. In: RILEM symposium, advances in concrete through science and engineering, Evanston, USA, March 22-24, CD-ROM, 12 pp

16. Brühwiler E, Denarié E, Habel K (2005) Ultra-high performance fibre reinforced concrete for advanced rehabilitation of bridges. In: Balasz GL, Borosnyoi A (eds) Proceedings of fib-symposium, Budapest, May 23-25, pp 951-956

17. Denarié E (2005) Structural rehabilitations with ultra-high performance fibre reinforced concretes (UHPFRC). In: Alexander M, Beushausen H-D, Dehn F, Moyo P (eds) Keynote lecture, ICCRRR 2005: international conference on concrete repair, rehabilitation and retrofitting, Cape Town, South Africa, 21-23 November. Taylor \& Francis, London (book with extended summaries and CD-ROM with full papers)

18. Kamen A (2007) Comportement au jeune Age et différé d'un béton écrouissant sous les effets thermomécaniques. Doctoral thesis No. 3827, The Ecole Polytechnique Fédérale de Lausanne, Suisse, 246 pp (in French)

19. Kovler K (1994) Testing system for determining the mechanical behavior of early age concrete under restrained and free uniaxial shrinkage. Mater Struct 27(170): 324-330

20. Bjontegaard O (1999) Thermal dilatation and autogenous deformation as driving forces to self-induced stresses in high performance concrete. Doctoral thesis, The University of Trondheim, Norway, 256 pp 
21. De Schutter G, Taerwe L (1997) Towards a more fundamental non-linear basic creep model for early age concrete. Mag Concr Res 49(180):195-200

22. Atrushi D (2003) Tensile and compressive creep of early age concrete: testing and modeling. Doctoral thesis, The University of Trondheim, Norway, $314 \mathrm{pp}$

23. Kamen A, Denarié E, Brühwiler E (2007) Mechanical behaviour of ultra high performance fibre reinforced concretes (UHPFRC) at early age, and under restraint. In: Pijaudier-Cabot G, Gérard B, Acker P, Hermès Publishing (eds) Proceedings of CONCREEP 7, Nantes, France, September 12-14, 2005, pp 591-596

24. Kamen A, Denarié E, Brühwiler E (2007) UHPFRC early age time dependent response-experimental characterisation and numerical analysis. In: Proceedings of the third international conference on structural engineering, mechanics and computation, Cape Town, South Africa, 10-12 September 2007, full paper and extended summaries

25. Bissonnette B, Boily D, Bastien J, Fafard M (2001) Tensile creep of concrete repair materials: recent experimental findings towards optimization. In: Ulm F-J, Bazant ZP, Wittmann FH (eds) Proceedings of CONCREEP 6, creep, shrinkage and durability mechanics of concrete and other quasi-brittle materials, pp 599-604

26. Gamble BR, Parrott L (1978) Creep of concrete in compression during drying and wetting. Mag Concr Res 30(104):129-138
27. Neville A, Brooks J (1987) Concrete technology. Longman Scientific and Technical

28. Bazant ZP, Prasannan S (1989) Solidification theory for concrete creep, part I: formulation, part II: verification and application. J Eng Mech 115:1691-1725

29. Bazant ZP (1972) Numerical determination of long-range stress history from strain history in concrete. Mater Struct 5:135-141

30. Bazant ZP, Wu ST (1974) Rate type creep law of aging concrete bases on Maxwell chain. Mater Struct 7(37): 45-60

31. Huet C (1980) Adaptation d'un algorithme de Bazant au calcul des multilames visco-élastiques vieillissants. Mater Struct 13(74):91-98 (in French)

32. Femmasse (2007) Software (MLS: multi-layer system), developed by Femmasse, on line help http://www. femmasse.nl

33. Bernard O (2000) Comportement à long terme des éléments de structure formés de bétons d'âges différents. Doctoral thesis No. 2283, The Ecole Polytechnique Fédérale de Lausanne, Suisse, 238 pp (in French)

34. Roelfstra PE (1989) A numerical approach to investigate the properties of concrete-numerical concrete. Doctoral thesis No. 788, The Ecole Polytechnique Fédérale de Lausanne, Suisse, 199 pp 